- separate uranium-235 from the heavier uranium-238 isotope. A number of outside organizations, including the FAS and ISIS, have focused on how efficiently those centrifuges can enrich uranium, measured as kilograms of enriched uranium produced per standard 'separative work unit' (kg SWU). This number would help indicate how quickly Iran, if it so chose, could enrich enough material for a nuclear weapon.

Barzashka bases her derivation of SWU on data provided by the International Atomic Energy Agency (IAEA), which conducts regular inspections of Iran's nuclear facilities. On the basis of those numbers, she estimates that Iran's ability to enrich uranium is increasing. This suggests that Stuxnet has not been as detrimental as Albright suggests, and that Iran has actually improved its overall efficiency with centrifuges.

The FAS entered the debate in 2009 (see 'Spinning the numbers') when Barzashka and Ivan Oelrich, a retired senior fellow at the FAS, using publicly available IAEA numbers, calculated Iran's centrifuge performance as around $0.44 \mathrm{~kg}$ SWU per year. Using the same methods, Barzashka's latest analysis finds $0.77 \mathrm{~kg}$ SWU per year. Both numbers are lower than those of ISIS, and lower than many other independent estimates. But Barzashka maintains that just as others were overestimating Iran's capabilities in the past, they are now perhaps overestimating the effect of the Stuxnet worm and ignoring evidence that Iran's capabilities are actually improving.

\section{SPINNNGG THE NUMBERS}

Estimates of Iran's pace of uranium enrichment have varied over time. Figures seem to converge but there is uncertainty about the facts behind the trend.

\begin{tabular}{ccl}
\multicolumn{2}{c}{ kg SWU/yr } & Source \\
\hline 16 MAY 2006 & 1.46 & $\begin{array}{l}\text { Jeffrey Lewis } \\
\text { go.nature.com/izqsmj }\end{array}$ \\
\hline 1 NOV 2007 & 2 & $\begin{array}{l}\text { David Albright } \\
\text { go.nature.com/ghrzfv }\end{array}$ \\
\hline 17 JAN 2008 & 1.36 & $\begin{array}{l}\text { Richard Garwin } \\
\text { go.nature.com/4psvtc }\end{array}$ \\
\hline 27 FEB 2009 & 2.2 & go.nature.com/ghrzfv \\
\hline 22 SEP 2009 & 2.1 & $\begin{array}{l}\text { Ali Akbar Salehi } \\
\text { go.nature.com/wp4kxs }\end{array}$ \\
\hline 25 SEP 2009 & 0.44 & $\begin{array}{l}\text { Ivan Oelrich \& } \\
\text { Ivanka Barzashka } \\
\text { go.nature.com/vnuhzz }\end{array}$ \\
\hline 21 JAN 2011 & 0.77 & $\begin{array}{l}\text { Ivanka Barzashka } \\
\text { go.nature.com/sihqyl }\end{array}$ \\
\hline 15 FEB 2011 & 0.9 & $\begin{array}{l}\text { David Albright et al. } \\
\text { go.nature.com/5rgzpa }\end{array}$ \\
\hline
\end{tabular}

Albright now places Iran's enrichment capacity at $0.9 \mathrm{~kg}$ SWU per year, partly on the basis of government information that is not available to other experts. This is a downward trend relative to earlier numbers from ISIS, but despite the fact the two groups' numbers seem to be converging, the conclusions that they draw from those numbers have continued to fuel an acrimonious debate.

In December 2010, Albright e-mailed the head of the FAS, calling Oelrich and
Barzashka's Iran estimates a "bogus claim”. Oelrich and Barzashka - their departures from the FAS were unrelated to the matter disagree. "Albright doesn't assume any value, he bases his value on expert opinion," says Oelrich. "And we don't assume any value; we calculate it based on IAEA results."

Albright says that if Iran were to pursue a nuclear weapon at full speed, it would take the country only about six months to enrich a sufficient quantity of uranium at Natanz. The Obama administration, according to Albright, uses a more conservative estimate of 10-14 months. Barzashka's latest estimate of five months is in close agreement with Albright.

Barzashka says that, in such a 'breakout scenario' of full-speed production, underestimating Iran's progress "takes away from the urgency of a diplomatic breakthrough".

But for some, the absolute numbers matter less than the debate itself. "The one thing we've learned from the Iraq debacle is that you have to have technical debates; everyone's assumptions have to be challenged," says Jacqueline Shire, a member of the United Nations Panel of Experts, which looks at the effectiveness of sanctions against Iran.

Shire, who used to work at ISIS, warns that getting "bogged down in SWU numbers" can also divert attention from the real issue. "One can very easily start to get buried in minutiae and lose sight of the big picture," she says, "which is to stop Iran from enriching uranium, and think creatively about how to do that." -

\title{
Marine biology network launches into choppy waters
}

\section{Ambitious European project hopes to navigate uncertain funding future.}

\section{BY NICOLA NOSENGO}

Oometimes good ideas take a while to be picked up. In 1872, Anton Dohrn, a $\checkmark$ pioneering German biologist, wrote a commentary in Nature proposing the foundation of "a net of scientific stations" along European coasts, focusing on marine biology (Nature $5,277-280 ; 1872)$. Almost 140 years later, an institute that bears Dohrn's name is leading a twenty-first-century realization of his idea.

The European Marine Biological Resource Centre (EMBRC) will launch this week at a meeting in Naples, Italy, with the Anton Dohrn Zoological Station in Naples (SZN) taking the lead. Linking 15 existing research centres in 8 countries (see 'Marine network'), the project will create an overarching organization for
European research on marine biology, and provide model organisms for studying fundamental molecular biology and for screening drug candidates, for example. But the project has yet to secure the ambitious budget needed to realize its full potential.

Its goal is to make experiments on marine organisms as easy and common as those on mice or fruitflies. "Most of the molecular biology we know today comes from terrestrial species," says SZN president Roberto di Lauro. "Genetics has mostly focused on Drosophila or the mouse because they are very easy to grow in a lab." Yet, he points out, most of the world's genetic diversity is found at sea, and some marine species are becoming useful model organisms. The sea squirt Ciona intestinalis, for example, is one of the closest invertebrate

relatives of humans and has had its genome sequenced, making it useful for a range of studies. Interest in marine organisms such as Ciona is growing rapidly outside the community of marine ecologists.

The EMBRC aims to select a few species as the best candidates to become model organisms and develop technologies to grow them in artificial seawater, and to study and modify their genes. These organisms will be made available to other institutes or companies, along with the technology and sup-

$\rightarrow$ NATURE.COM To read Anton Dohrn's original vision, see: go.nature.com/Wel8cN port needed to study them. The centre could also produce strains of genetically modified organisms on request for institutes that want 


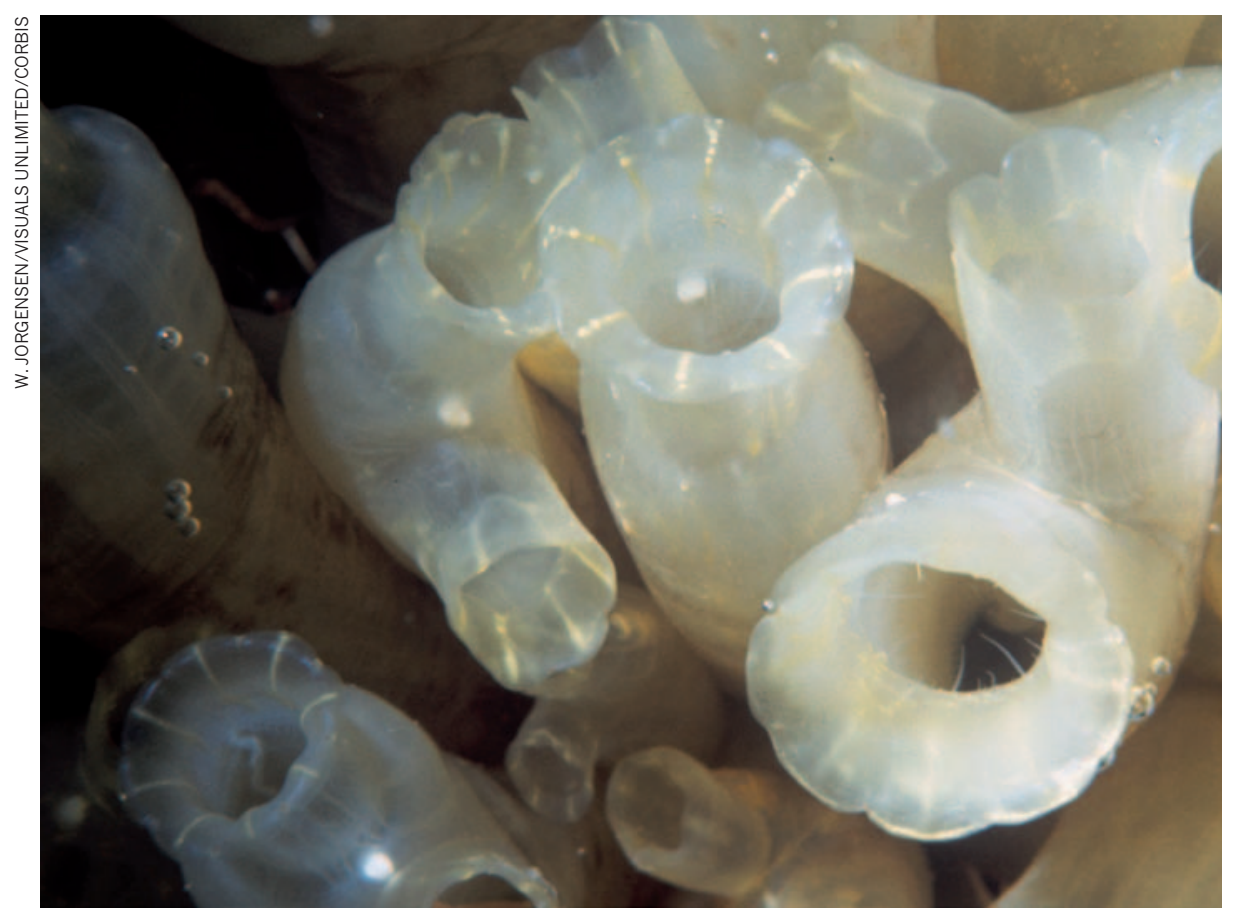

The sea squirt could become a top model organism at Europe's new marine biology centre.

to grow them on their own premises, as now happens with rodents.

In the preparatory phase, lasting 3 years, $€ 3.9$ million (US $\$ 5.3$ million) from the European Commission will be used to plan the organizational structure of the new network. "Most of the work will be about managing data," says Detlev Arendt, a developmental biologist at the European Molecular Biology Laboratory in Heidelberg, Germany, who will lead the design of the EMBRC's bioinformatics infrastructure.

The next stage will see partner institutes spend $€ 100$ million over 5 years to build up their research capacity. Once the centre is operational, each country will pay for the costs of its own institutes, and will also contribute to the budget of the coordinating body.

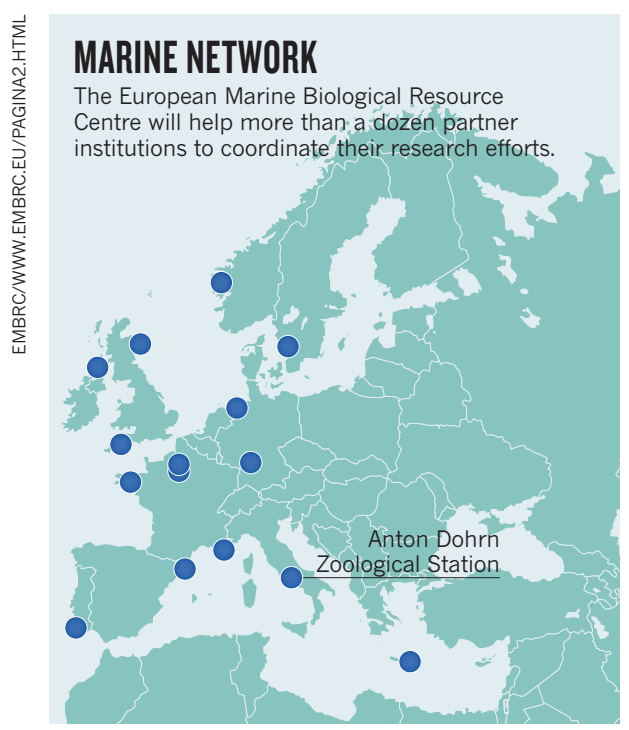

This is where some problems might arise. Six other research-infrastructure networks launched by the European Commission in 2006 are now at the end of their preparatory phase, and some are having trouble getting the funds needed to make further progress. "Things are going slower than we expected," admits Jean-Emmanuel Faure of the European Commission's Directorate General for Research. "The timing is bad, with the economic crisis hitting some countries very hard."

Ireland, for example, has withdrawn its financial support to the European Clinical Research Infrastructures Network, based in Paris. And the European Commission has extended the preparatory phase of INSTRUCT, a similar initiative in structural biology, giving it two more years to look for alternative funding sources.

If it can secure funding, the EMBRC has the potential to become a keystone in a global network of marine centres, according to Gary Borisy, director of the Marine Biological Laboratory in Woods Hole, Massachusetts. "We have something similar in the United States with the National Association of Marine Laboratories, but we are not that advanced in terms of standardizing technologies," he says. Borisy hopes that the EMBRC will create opportunities for collaborations between Europe, the United States and Japan, which is also very active in marine genomics. "The first thing to do would be to agree on a few model species and make them worldwide standards," he says.

Making the EMBRC part of a global network is the ultimate long-term goal, agrees di Lauro. The challenge, as Dohrn noted 140 years ago, is that "governments will not easily be induced to sacrifice much money for the progress of this science". 